Ryan, F. J. \& Wainwright, L. K. (1954). J. gen. Microbiol. 11, 364-379.

\title{
Nuclear Segregation and the Growth of Clones of Spontaneous Mutants of Bacteria
}

\author{
BY F. J. RYAN AND LILLIAN K. WAINWRIGHT \\ Department of Zoology, Columbia University, New York 27
}

SUMMARY: An investigation of the rate of increase of spontaneous mutants and the subsequent increase in mutant proportion in a bacterial culture revealed discrepancies between the observed results and those expected on the assumption that mutant and parent grew with equal rates. These discrepancies could not be accounted for in terms of a selective difference between established mutants and their parents since, when the two were mixed together in reconstruction experiments, they fared equally well for hundreds of generations. Rather the discrepancies indicated a difference between parents and new mutants. The data were consistent with the hypothesis that the mutation occurred independently among one of four mutable units (nuclei) and that the mutant nucleus was 'dominant' over its sister non-mutant nuclei in the heterocaryon so formed. As a consequence, a delay of two generations ensued before the mutant unit segregated into the homocaryotic ancestor of a mutant clone. This process delayed the onset of an increase in mutant numbers after mutation. The accurate prediction of the pseudo-equilibrium level of mutants, based on verifiable assumptions of periodic selection, mutation and segregation lag, is added evidence for the occurrence of a two-generation delay before the increase of the mutant clone. This phenomenon, called segregation lag, is a source of error in the calculation of mutation rate by methods involving the numbers of mutants found in bacterial cultures. Furthermore, because bacteria may be multinucleate, the rate of mutation/bacterium/generation is not the same as the rate of mutation/mutable unit (nucleus)/generation.

That a growing bacterium may contain more than one body consisting of deoxyribonucleic acid is well known. Witkin (1951) was the first, however, to offer direct evidence indicating that these bodies contain genetic material and are the counterparts of nuclei. Her evidence was threefold. First, the ratio of wholly mutant colonies to those containing mutant sectors was proportional to the ratio of uninucleate bacteria in the irradiated culture which gave rise to the colonies. This finding is consistent with the hypothesis that sectored colonies originate through segregation of the nuclear bodies during growth. Secondly, there was a proportionality between the frequency of induced mutants, whole and sectored, and the frequency of bacteria with more than one nuclear body. Finally, there was some correlation between the types of sectored colonies and the most frequent number of nuclear bodies/multinucleate cell; cultures with mostly binucleate bacteria gave rise predominantly to half sectors while cultures consisting for the most part of cells with four nuclei gave rise predominantly to quarter sectors. A more extensive correlation was not attempted because of the difficulty in determining nuclear numbers.

This difficulty is even greater with bacteria that have been grown on chemically defined media. Yet it is sometimes necessary to know the average number 
of similar units capable of independent mutation in bacteria growing under such conditions. Consider the case where a mutation occurs in one of two identical units within a bacterium. If the mutant character were recessive it would not express itself until that bacterium had divided and given rise to two daughter cells, one homocaryotic for mutant and the other for non-mutant units. The mutation would seem to have occurred in the mutant daughter and hence the mutation rate would be underestimated by a factor of one half. If the mutant character were dominant, and there were no delay in the physiological development of the phenotype (no phenotypic lag), the first bacterium in which the mutation had occurred would express the mutant character. After the first

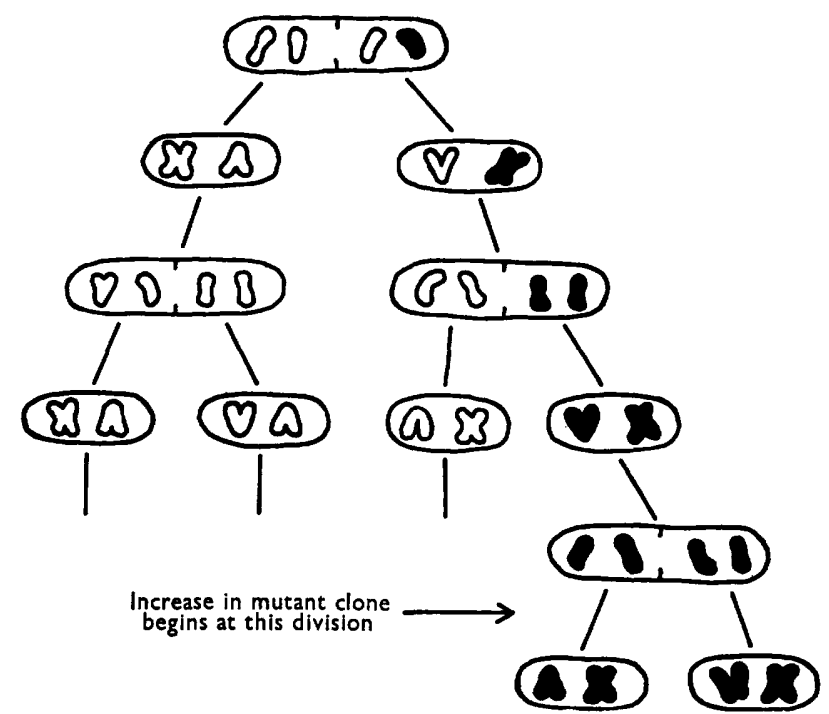

Fig. 1. Diagram of the segregation of a mutant nucleus from its non-mutant sister nuclei in a heterocaryotic bacterial cell. The assumptions are that: (1) there are four nuclear bodies, with regular segregation and thus 2 generations of segregation lag; $(2)$ the mutation is 'dominant' in heterocaryons; (3) there is no phenotypic delay. Thus, throughout the first two generations there is but one mutant present in the clone. The increase in the mutant clone begins at the third division.

division the number of mutants in that clone would not yet have increased because of the segregation of mutant from non-mutant units. Only after the homocaryotic mutant daughter had divided would the number of mutants increase (Fig. 1). This segregation lag acts like selection against the mutants inasmuch as it depresses their rate of increase in a culture. It is thus a source of error in calculating mutation rate, mutant distributions and the kinetics of population change.

Where segregation lag is in operation, the population of mutants will increase as though they were at a selective disadvantage, but when mutant and parent are put in competition in artificial mixtures the mutant need not be overgrown. Such a situation has been found with a histidine-requiring $\left(\mathrm{h}^{-}\right)$ strain and its independent $\left(\mathrm{h}^{+}\right)$mutant. No selective differences could be observed between them in extensive tests. Yet the increase in numbers of $h^{+}$ 
mutants was depressed below that expected from experimentally determined mutation rates and the assumption of no selective differences.

This paper will deal with experiments designed to reveal and measure the extent of segregation lag in this system and hence the average number of mutable units in these bacteria. The information obtained will be related to the problems of making a reliable estimate of the mutation rate and of developing a correct expression for the dynamics of population change.

\section{MATERIALS AND METHODS}

The parent strain used in these experiments was a histidine-requiring mutant $\left(\mathrm{h}^{-}\right)$of Escherichia coli (Bacterium coli), strain 15. The manner of cultivating it, the composition of the chemically defined medium and other technical details are described elsewhere (Ryan \& Schneider, 1948). Unless otherwise indicated, the glucose content of the medium was $0.5 \%(\mathrm{w} / \mathrm{v})$ and the cultures were unshaken during growth. The $\mathrm{h}^{-}$bacteria mutate to a histidine independent state $\left(\mathrm{h}^{+}\right)$, and the numbers of $\mathrm{h}^{+}$mutants can be determined by plating cultures, washed in $0.9 \%(\mathrm{w} / \mathrm{v})$ saline, into agar devoid of histidine where the $\mathrm{h}^{-}$parents do not grow. That this procedure reliably measures the number of $\mathrm{h}^{+}$organisms in the culture plated has been demonstrated elsewhere (Ryan \& Schneider, 1949). That washing by centrifugation and resuspension resulted in no significant loss of bacteria was shown in eleven experiments where plating washed cultures yielded $98 \%$ of the number of colonies found upon plating unwashed cultures, with the total numbers of bacteria varying between $3 \cdot 1 \times 10^{2}$ and $7 \cdot 3 \times 10^{8} / \mathrm{ml}$. Platings of both $\mathrm{h}^{+}$and $\mathrm{h}^{-}$bacteria, always done in duplicate, were made with saline dilutions designed to yield $c .50 \mathrm{~h}^{+}$or $\mathrm{h}^{-}$colonies/plate. Under such conditions the variance of numbers was approximately equal to the mean as would be expected if the only important error was that introduced by random sampling.

The $\mathrm{h}^{+}$mutants produced in these experiments formed a homogeneous group. Not only did they all grow at the same rate and to the same extent, but, unlike some growth-factor-independent mutants (Davis, 1950), they did not vary significantly in the amount of histidine they produced. As a matter of fact, they did not excrete appreciable amounts into the medium, since only extremely rarely were satellite colonies or haloes of growth formed by $\mathrm{h}^{-}$ bacteria crowded around the mutant $h^{+}$colonies. These $h^{+}$mutants were probably not due to a mixture of suppressor- and true back-mutations (Witkin \& Kennedy, 1951) because Lieb (1951) showed, by studying nineteen randomly isolated $\mathrm{h}^{+}$reversions of independent origin, that their rates of mutation to the $\mathrm{h}^{-}$state were the same and averaged $1.2 \times 10^{-6} /$ bacterium/generation. Although mutability is an extremely sensitive test, a critical decision cannot be made since, despite repeated attempts to introduce $\mathbf{F}^{+}$factor (Cavalli, Lederberg \& Lederberg, 1953) into strain 15, sexual crosses have been unsuccessful.

In some experiments organisms were employed which carried an additional genetic marker lac-, one which prevented the fermentation of lactose. A marked strain $\left(\mathrm{h}^{-} \mathrm{lac}^{-}\right)$was obtained after exposure to ultraviolet light of $\mathrm{h}^{-}$ bacteria on the surface of Difco-Endo agar plates until a survival of $c .10^{-6}$ was obtained. From the $\mathrm{h}^{-} \mathrm{lac}^{-}$stock, 10 independent $\mathrm{h}^{+} \mathrm{lac}^{-}$strains were 
secured after plating into medium devoid of histidine. When $\mathrm{h}^{+} \mathrm{lac}^{-}$bacteria were to be added, for example, to a culture of their $\mathrm{h}^{-} \mathrm{lac}^{+}$progenitor, all 10 of the $\mathrm{h}^{+} \mathrm{lac}^{-}$strains were separately grown and then mixed together in equal proportions. A sample of this mixture was added to the $\mathrm{h}^{-} \mathrm{lac}^{+}$culture. Similarly, 10 cultures of independently mutated $\mathrm{h}^{+} \mathrm{lac}^{+}$were used for additions to $h^{-}$lac- bacteria and, when fitter-type $h^{-}$and $h^{+}$bacteria were isolated after serial transfer, 10 stocks of each were established and all 10 used whenever possible.

Diagnosis of the proportion of lac- bacteria in a mixed culture was made in early experiments by streaking from colonies on to the surfaces of DifcoEndo or eosin-methylene blue indicator plates where lac $^{-}$bacteria formed uncoloured colonies in contrast to lac ${ }^{+}$bacteria which formed purple colonies. In later experiments the replication technique of Lederberg \& Lederberg (1952) was employed.

The neutral character of the stable 'lac' markers was shown in a number of ways. The $\mathrm{h}^{-} \mathrm{lac}^{+}, \mathrm{h}^{-} \mathrm{lac}^{-}, \mathrm{h}^{+} \mathrm{lac}^{+}$and $\mathrm{h}^{+} \mathrm{lac}^{-}$strains, when grown separately on medium containing histidine, had indistinguishable rates and final levels of growth, and the $h^{-}$stocks contained the same numbers of $h^{+}$mutants. When, in four experiments, mixtures of $\mathrm{h}^{+} \mathrm{lac}^{-}$and $\mathrm{h}^{+} \mathrm{lac}^{+}$, with an average initial ratio of $63: 37$, were grown for 232 generations the final average proportion was $72: 28$. It can be concluded that the introduction of the lac marker did not affect to any great extent the selective qualities of the strain. Further evidence establishing this point will be presented below.

All strains used in these experiments were purified by at least two repeated isolations from Difco-Endo agar. Samples of the stocks were then spread on surfaces of nutrient agar containing $0.9 \%(\mathrm{w} / \mathrm{v}) \mathrm{NaCl}$ where their sensitivity to the seven T-coliphages was tested. All, like the parent strain, were sensitive only to phage $\mathbf{T}_{2}$.

In those cases where cultures were serially transferred the procedure was as follows. Growth was allowed to occur in $125 \mathrm{ml}$. Erlenmeyer flasks containing $50 \mathrm{ml}$. basal medium supplemented with $25 \mu \mathrm{g}$. L-histidine monohydrochloride/ $\mathrm{ml}$. Unless otherwise mentioned, the inoculum consisted of $0.5 \mathrm{ml}$. of such cultures which had entered the stationary phase at $37^{\circ}$ and were between 8 and $16 \mathrm{hr}$. old. Such an inoculum contained $c .2 .5 \times 10^{8} \mathrm{~h}^{-}$bacteria which, during $6 \mathrm{hr}$. of growth in $50 \mathrm{ml}$. of fresh medium, produced c. $2.5 \times 10^{10}$ progeny in 6.64 generations. It was necessary to employ such a large inoculum because the frequency of $\mathrm{h}+$ bacteria at the beginning of the experiments was as low as $10^{-7}$. In such an event $0.5 \mathrm{ml}$. contained c. $25 \mathrm{~h}^{+}$bacteria, a number which is not likely to be subject to drastic distortion by sampling error. Gradually the number of $\mathrm{h}^{+}$organisms in the inocula became much greater, in some cases being as large as $\mathbf{1 0 0 0}$. It is felt that adequate samples of the previous population were taken for inoculation into the next.

The optical density of cultures in the stationary phase of growth remained constant for a matter of many days. The gradual death of bacteria began after the first day, but until that time the viable number was equal to the total number as determined with a Petroff-Hauser counting chamber; for example, 
in two determinations made after the bacteria were in the stationary phase for $12 \mathrm{hr}$., the viable number was $5 \cdot 2 \times 10^{8} / \mathrm{ml}$. while the total number was $4.8 \times 10^{8} / \mathrm{ml}$. During the period within which samples were taken routinely for inoculation, there was no detectable shift in the proportions of $h^{+}$and $h^{-}$ bacteria (Table 1).

\section{Table 1. Proportion of $h^{+}$bacteria during the early part of the stationary phase of growth}

The proportion of $h^{+}$bacteria was varied in the last three experiments by introducing extra $\mathrm{h}^{+}$organisms with the inoculum.

\begin{tabular}{|c|c|c|c|c|}
\hline Expt. & $\begin{array}{c}\text { Age of culture } \\
(\mathrm{hr} .)\end{array}$ & $\begin{array}{c}\text { No. of } \mathrm{h}^{-} \\
\text {bacteria per ml. }\end{array}$ & $\begin{array}{c}\text { No. of } h^{+} \\
\text {bacteria per ml. }\end{array}$ & $\begin{array}{c}\text { Frequency of } \\
\mathrm{h}+\text { bacteria }\end{array}$ \\
\hline 1 & $\begin{array}{l}8 \cdot 0 \\
12 \\
16\end{array}$ & $\begin{array}{l}5.3 \times 10^{8} \\
5.6 \times 10^{8} \\
5.0 \times 10^{8}\end{array}$ & $\begin{array}{l}1.2 \times 10^{2} \\
1.1 \times 10^{2} \\
9.9 \times 10^{1}\end{array}$ & $\begin{array}{l}2.3 \times 10^{-7} \\
2.0 \times 10^{-7} \\
2.0 \times 10^{-7}\end{array}$ \\
\hline 2 & $\begin{array}{c}0 \\
6 \cdot 0 \\
12\end{array}$ & $\begin{array}{l}1 \cdot 0 \times 10^{7} \\
2 \cdot 3 \times 10^{8} \\
5 \cdot 1 \times 10^{8}\end{array}$ & $\begin{array}{c}4.7 \\
1.2 \times 10^{2} \\
2 \cdot 6 \times 10^{2}\end{array}$ & $\begin{array}{l}4.7 \times 10^{-7} \\
5.2 \times 10^{-7} \\
5.1 \times 10^{-7}\end{array}$ \\
\hline $\mathbf{3}$ & $\begin{array}{l}12 \\
18\end{array}$ & $\begin{array}{l}5.8 \times 10^{8} \\
5.4 \times 10^{8}\end{array}$ & $\begin{array}{l}1.7 \times 10^{3} \\
1.7 \times 10^{8}\end{array}$ & $\begin{array}{l}2.9 \times 10^{-6} \\
3.2 \times 10^{-6}\end{array}$ \\
\hline 4 & $\begin{array}{l}9 \cdot 7 \\
12 \\
16\end{array}$ & $\begin{array}{l}4.5 \times 10^{8} \\
4.5 \times 10^{8} \\
4.1 \times 10^{8}\end{array}$ & $\begin{array}{l}4.5 \times 10^{3} \\
4.6 \times 10^{3} \\
3.9 \times 10^{3}\end{array}$ & $\begin{array}{l}1.0 \times 10^{-5} \\
1.0 \times 10^{-5} \\
9.5 \times 10^{-4}\end{array}$ \\
\hline
\end{tabular}

Initial increase of $h^{+}$bacteria in $h^{-}$cultures

In order to determine the rate at which $\mathrm{h}^{+}$bacteria increased in number after they first arose by mutation in $\mathrm{h}^{-}$cultures, $c .50 \mathrm{~h}^{-}$bacteria were inoculated into a flask containing $50 \mathrm{ml}$. basal medium + histidine. At various times after inoculation, samples, varying in different experiments from 5 to $12 \mathrm{ml}$. were removed and the numbers of $h^{+}$and $h^{-}$bacteria determined by differential plating. The estimated total numbers of bacteria present at different times are shown in Fig. 2. The data were collected from fourteen different experiments and the individual growth curves of the $h^{-}$bacteria showed lag periods (defined as the time at which the straight line describing logarithmic growth intercepts the level of inoculum size) varying between 0 and $5 \mathrm{hr}$. That the logarithmic rates of growth were the same is shown by the goodness of fit when the lag periods were equated to the average of $3.75 \mathrm{hr}$. as was done in the construction of Fig. 2. Even after a corresponding adjustment, the individual curves for the $h^{+}$bacteria intercepted the level of one bacterium at times varying from 15.5 to $20 \mathrm{hr}$. This variation is to be expected if mutations occur at random, for in some cultures the first mutation takes place earlier than in others. In order to portray the average rate of increase of the $\mathrm{h}^{+}$bacteria, their individual curves were equated at the level of $10^{3}$ bacteria with the average curve. It will be observed that the $\mathrm{h}^{-}$bacteria grew to a final population of $2.5 \times 10^{10}$ organisms, the generation time during the logarithmic phase being about $50 \mathrm{~min}$. The $\mathrm{h}^{+}$bacteria increased at a constant rate which cannot be distinguished from that of the $\mathrm{h}^{-}$bacteria.

This fact was surprising inasmuch as the total increase in $\mathrm{h}^{+}$bacteria, assuming a constant mutation rate and no selection for or against the mutant, 


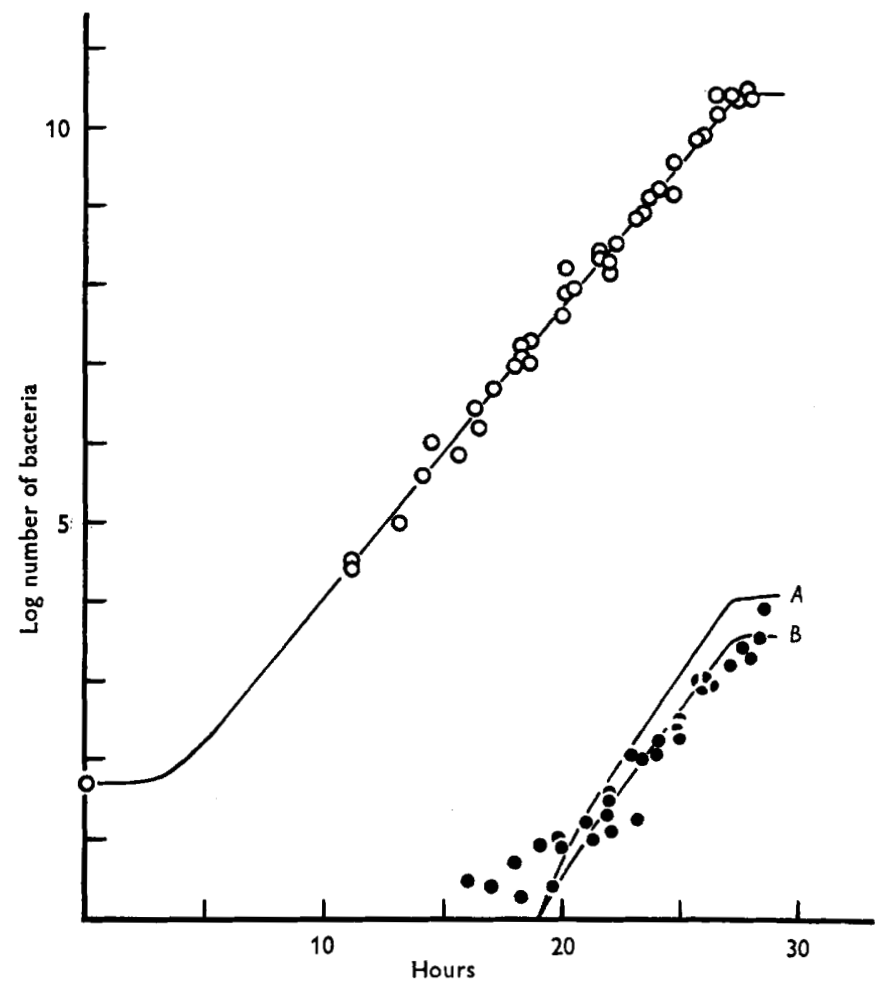

Fig. 2. The rate of increase in the number of $h^{-}$bacteria (open circles) and the $h^{+}$mutants (black circles) arising among them as determined by sampling suspensions of cultures which contained histidine and had been inoculated with a small number of $h^{-}$organisms. The ordinate measures the $\log _{10}$ of the number of bacteria; the abscissa, the number of hours elapsing between inoculation and sampling. The text describes how the data were used to construct this figure. Curve $A$ through the numbers of $\mathrm{h}^{+}$bacteria (black circles) describes the behaviour expected on the assumption of no segregation lag. The curve $B$ through the same points is that expected if segregation lag lasts for two generations.

should follow the series 1, 4, 12, 32, .., if the following model be valid. Assume that, on the average, when there are $n$ parental $h^{-}$bacteria, the first mutation occurs. When the parents have undergone a division, so has the mutant; but among the parents, now double in number, twice as many mutations occur on the average. The increase of parents and mutants would then take place as follows:

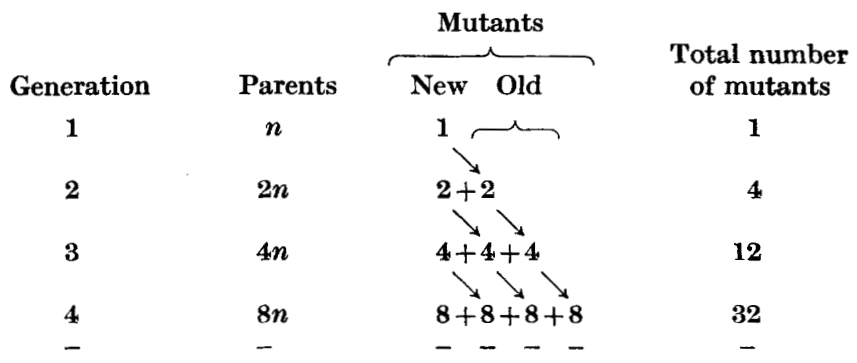


The new mutants have been added at each generation to the left column of the triangle and their progeny are carried forward as the arrows indicate. Other models are possible (Armitage, 1953; Kendall, 1953) but all call for a greater than logarithmic increase in the number of mutants. Yet the actual increase seems to be nearly logarithmic; curve $A$, which does not fit the points in Fig. 2, is that calculated from the above model, where the number of mutants at any generation, $g$, is equal, on the average, to $g \times 2^{g-1}$.

If, after the first mutant appeared, no further mutations occurred, a logarithmic series would be obtained. This hypothesis has been tested by determining the proportions of $\mathrm{h}^{+}$mutants that carry parental markers in a mixture of $\mathrm{h}^{-} \mathrm{lac}^{+}$and $\mathrm{h}-$ lac- bacteria. About 50 organisms of each strain were either inoculated together into $50 \mathrm{ml}$. defined medium + histidine, or the $\mathrm{h}^{-} \mathrm{lac}^{+}$bacteria were inoculated $1 \mathrm{hr}$. after the $\mathrm{h}^{-} \mathrm{lac}^{-}$. Samples of the mixed cultures were taken at different times and characterized for their $h^{-}$and $h^{+}$ content. The results shown in Table 2 are averages of two experiments and each percentage is based upon the isolation and characterization of at least 40 colonies. The occurrence of a mutation in one $\mathrm{h}^{-}$strain neither prevented the occurrence of mutations in the other nor seemed to change at all the numbers of mutants produced by the second strain. This evidence is inconsistent with the hypothesis that the logarithmic increase in number of $h^{+}$ bacteria is due to interference with subsequent mutation.

Table 2. The lack of influence of one mutation on the occurrence of others

\begin{tabular}{|c|c|c|c|c|c|}
\hline \multirow[b]{2}{*}{$\begin{array}{c}\text { Age of } \\
\text { culture } \\
\text { (hr.) }\end{array}$} & \multirow[b]{2}{*}{$\begin{array}{c}\text { No. of } h^{-} \\
\text {bacteria per ml. }\end{array}$} & \multicolumn{4}{|c|}{ Percentage of lac ${ }^{+}$bacteria } \\
\hline & & $\begin{array}{c}\text { No. of } \mathbf{h}^{+} \\
\text {bacteria per ml. }\end{array}$ & $\begin{array}{l}\text { Frequency of } \\
\mathbf{h}^{+} \text {bacteria }\end{array}$ & $\begin{array}{c}\text { among } \\
\mathbf{h}-\text { bacteria }\end{array}$ & $\begin{array}{c}\text { among } \\
\mathbf{h}+\text { bacteria }\end{array}$ \\
\hline \multicolumn{6}{|c|}{$\mathrm{h}^{-}$lac- inoculated with $\mathrm{h}^{-} \mathrm{lac}^{+}$} \\
\hline 20 & $\mathbf{2 \cdot 3} \times 10^{7}$ & $\mathbf{3} \cdot \mathbf{1}$ & $1.3 \times 10^{-7}$ & $59 \cdot 0$ & $69 \cdot 3$ \\
\hline 23 & $2 \cdot 2 \times 10^{8}$ & $1.8 \times 10^{1}$ & $8.2 \times 10^{-8}$ & $72 \cdot 7$ & $72 \cdot 0$ \\
\hline 27 & $5 \cdot 2 \times 10^{8}$ & $5 \cdot 9 \times 10^{1}$ & $1 \cdot 1 \times 10^{-7}$ & $73 \cdot 3$ & $67 \cdot 0$ \\
\hline \multicolumn{6}{|c|}{$h^{-}$lac ${ }^{-}$inoculated one hour before $h^{-}$lac $^{+}$} \\
\hline 20 & $1.8 \times 10^{7}$ & $1 \cdot 7$ & $9 \cdot 4 \times 10^{-8}$ & $28 \cdot 0$ & $\mathbf{2 5 \cdot 4}$ \\
\hline 23 & $1 \cdot 1 \times 10^{8}$ & $1.4 \times 10^{1}$ & $1 \cdot 3 \times 10^{-7}$ & $\mathbf{3 6} \cdot \mathbf{0}$ & $18 \cdot 0$ \\
\hline 27 & $5 \cdot 2 \times 10^{8}$ & $6.8 \times 10^{1}$ & $1.3 \times 10^{-7}$ & $30 \cdot 6$ & $\mathbf{3 6} \cdot \mathbf{0}$ \\
\hline
\end{tabular}

On the other hand, if each mutant after its appearance survived but did not divide, or divided very slowly, an increase series of $1,3,7,15, \ldots, 2^{g}-1$, which is almost logarithmic, would be obtained. This hypothesis of almost complete selection against $h^{+}$mutants was tested by reconstruction experiments in which known numbers of $h^{+}$bacteria were added to $h^{-}$cultures. Cultures of $\mathrm{h}^{-}$bacteria, begun with an inoculum of $c .50$ organisms and serially transferred, have a proportion of $c .10^{-7} \mathrm{~h}^{+}$organisms immediately after the first mutation; the proportion then rises to a pseudo-equilibrium of $c .10^{-6}$ which is achieved after more than 100 generations (Atwood, Schneider \& Ryan, 1951). As a consequence simple reconstruction experiments can be interpreted only when $h^{+}$bacteria are added in numbers large enough to escape significant additions by the mutations occurring among the $\mathrm{h}^{-}$bacteria. In order to be 
able to study selection at ratios of $\mathrm{h}^{+}$to $\mathrm{h}^{-}$bacteria approximating those existing when mutations first occur advantage was taken of the lac marker. Thus, $\mathrm{h}^{+} \mathrm{lac}^{-}$bacteria were added to cultures of $\mathrm{h}^{-} \mathrm{lac}^{+}$organisms in various proportions, the mixtures were serially transferred and their composition determined at intervals. In order to ascertain a possible influence of the $\mathrm{lac}^{+-} \mathrm{lac}^{-}$difference on the outcome of these experiments the reciprocal mixture, $\mathrm{h}^{+} \mathrm{lac}^{+}$in $\mathrm{h}^{-} \mathrm{lac}^{-}$, was studied.

The position of the lac marker was of no consequence and no mixture exhibited any selective difference between $h^{+}$and $h^{-}$bacteria. Thus in 19 experiments, with markers in both combinations and where the initial $\mathrm{h}^{+}$proportions were at various levels between $10^{-4}$ and $10^{-6}$, the proportions after 166 generations of growth were, on the average, $96.6 \%$ of those at the start. In 16 experiments, where the initial $\mathrm{h}^{+}$proportion was $c .10^{-7}$, the proportion after 60 generations was found to be, on the average, $104 \%$ of that at the beginning. Again in 5 experiments, where the initial proportions were between 46 and $62 \%$, the proportions after between 28 and 133 generations changed by an average factor of $\mathbf{0 . 9 5 2}$.

Thus, $\mathbf{h}^{-}$and $\mathbf{h}^{+}$organisms fared equally well in competition. After some 200 generations, however, a fitter-type mutant appeared, usually in the preponderant component of the mixture, and eliminated all other types present. An analysis of this independent phenomenon is presented elsewhere (Atwood et al. 1951). It is of interest here only to note that for more than a hundred generations selective difference between $\mathrm{h}^{+}$and $\mathrm{h}$ - bacteria cannot be observed. Hence, drastic selection cannot explain the discrepancy shown in Fig. 2 unless there are differences between new mutants, whose behaviour the figure portrays, and established mutants of the sort used in the reconstruction experiments.

One difference between new and old mutants lies in the fact that the former would be heterocaryotic if the mutation occurred independently and in only one of the several nuclei present. Bacteria from established mutant cultures would be homocaryotic for mutant nuclei since the segregation shown in Fig. 1 would already have taken place during the initiation of the colony from which the mutant clone was first isolated. The activity of growth-factorindependent mutants in heterozygotes (Lederberg, 1949) and the fact that they probably occur as zero-point mutants (Ryan, 1954; Ryan, Fried \& Schwartz, 1954) would indicate that the $\mathrm{h}^{+}$condition is dominant. If this were true and the development of the $\mathrm{h}^{+}$phenotype required less than a generation, then the lag in the increase of the mutant clone, imposed by the necessity for the segregation of mutant from non-mutant nuclei, would have the following effect on the rise of mutant number. Assume that each bacterium has each genetic unit represented 4 times and that mutations occur rarely and at random among them. A two-generation segregation delay $(\Delta=2)$ would result (Fig. 1), and the effect on the model discussed above would be as shown on p. 372. This series, which the formulation $2^{g-3}(g+4)$ describes for all but the first generation, is very close to logarithmic and could fit the data in Fig. 2 (curve $B$ ). 


\begin{tabular}{|c|c|c|c|}
\hline \multirow[b]{2}{*}{ Generation } & \multirow[b]{2}{*}{ Parents } & Mutants & \multirow{2}{*}{$\begin{array}{l}\text { Total number } \\
\text { of mutants }\end{array}$} \\
\hline & & New Old & \\
\hline $\mathbf{1}$ & $n$ & $\longrightarrow$ & $\mathbf{1}$ \\
\hline 2 & $2 n$ & $2+$ & 3 \\
\hline 3 & $4 n$ & & 7 \\
\hline 4 & $8 n$ & $8+4+2+2$ & 16 \\
\hline - & - & $-\quad--$ & - \\
\hline
\end{tabular}

The non-segregation-lag model also predicts an almost logarithmic rate of increase of $\mathrm{h}^{+}$mutants after their number in the culture becomes large. The most sensitive portion of the mutant increase curve for a discrimination between the two models is the low region. Yet it is just here that the data in Fig. 2 are least accurate. The data for numbers of $h^{+}$bacteria less than 30 are based on counts of 1 to 6 bacteria in the samples. Such counts are inaccurate in themselves and, furthermore, although mutation on the plates does not occur to a great extent when washed agar is used, the occurrence of only one or two plate mutations would profoundly distort counts of such small numbers of $\mathrm{h}+$ bacteria. For this reason data were collected by another method which did not involve the use of agar. At different times samples were taken from a $50 \mathrm{ml}$. culture of $\mathrm{h}$ - bacteria, washed, resuspended in defined medium devoid of histidine and distributed, with or without dilution, in a series of $1 \mathrm{ml}$. samples. If any of these samples contained one or more $\mathrm{h}^{+}$bacteria, visible turbidity resulted from their growth; if no $h^{+}$bacteria were introduced, no turbidity resulted, for the $\mathrm{h}^{-}$bacteria present did not grow in the absence of histidine.* By the use of the fraction of the cultures which did not contain $\mathrm{h}^{+}$ bacteria and the Poisson formulation, it was possible to calculate the average number of $h^{+}$bacteria and from that, the total number that were distributed. In this way errors resulting from mutation on the plates were avoided.

In order to circumvent errors implicit in the sampling of small numbers of mutants the entire contents of whole cultures would have to be assayed. But, because in different cultures the first and succeeding mutations may occur at different times, for every sampling time a large number of cultures would have to be assayed. One might then suppose that the average number of mutants found could be used to construct an increase curve. This procedure is, however,

* In such stationary cultures of $\mathrm{h}^{-}$bacteria the $\mathrm{h}^{+}$mutants contained grow to visible turbidity in about $24 \mathrm{hr}$. at $37^{\circ}$ as was shown by the introduction of single marked $\mathrm{h}^{+}$ bacteria. Nevertheless, for a period of about 10 days adaptive overgrowths continued to occur with low frequency in stationary $h^{-}$cultures. It was possible to show that these late appearing adaptations were due to $h^{+}$bacteria which were not present at the time of distribution but which appeared later. Perhaps they represent mutations of $h$ - bacteria in the stationary phase but they may also be due to release, during the stationary phase, of genotypically $h^{+}$bacteria from a phenotypic lag. Evidence secured to make a distinction between these possibilities will be presented elsewhere. In connexion with Fig. 3, however, it should be noted that these stationary phase adaptations were not counted, since observation was limited to the $24 \mathrm{hr}$. period required for the overgrowth of $h^{+}$bacteria originally present in the sample. 
invalid on theoretical grounds. The individual populations of the large number of cultures form in reality one large population containing a number of mutants equal to the number of cultures multiplied by the average number of mutants/culture. As was previously pointed out, when the mutant number is large the expected curves, whatever the hypothesis, all approximate to a logarithmic increase; discrimination between experimental and theoretical

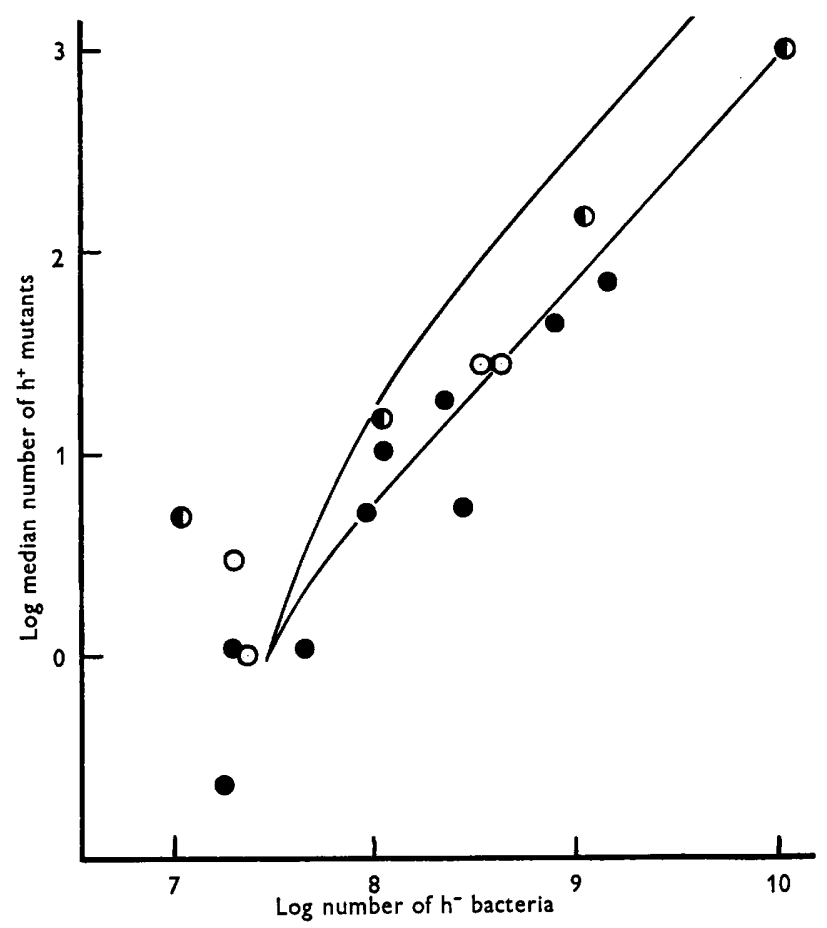

Fig. 3. The rate of increase in the median number of $h^{+}$mutants among a series of similar cultures of spontaneously mutating $\mathrm{h}^{-}$bacteria. The data presented as black circles came from three different experiments in which the whole contents of each culture were assayed by the method of fractionation in liquid medium described in the text. In two of these experiments the bacteria were washed in a refrigerated centrifuge to prevent all growth from the moment of sampling. The data presented as open circles came from two experiments in which at a given time a series of $2 \mathrm{ml}$. suspensions, washed in the cold, were plated whole along with three saline rinsings. The data presented as half circles are the medians of the values found in the fourteen experiments summarized in Fig. 2. Each point is the median of between 10 and 18 cultures. The ordinate measures the $\log _{10}$ of the median number of $h^{+}$mutants; the abscissa, the $\log _{10}$ of the average number of $h^{-}$bacteria in the series of cultures assayed. The upper curve is theoretical (see text); the lower was drawn by eye to fit the experimental points.

curves must be made in regions where the number of mutants is very small. The value of the average number of mutants is, furthermore, seriously affected by chance early mutations contributing disproportionately large bursts of mutants. The median number of mutants is, on the other hand, not so affected. Fortunately, through the efforts of Lea \& Coulson (1949), the median of the numbers of mutants in a series of different cultures has been calculated for 
different average numbers of mutations on the assumptions of random mutation and equal growth of mutant and parent. Thus a theoretical curve for the increase of the median numbers of mutants can be compared with that observed for a large number of cultures whose entire contents were assayed at different times.

Fig. 3 represents such a comparison. Clearly the theoretical curve, constructed on the assumption that the mutants increase in number immediately without a segregation lag, does not fit the data. The equations for the distribution of the numbers of mutants among replicate cultures, where the mutants are assumed to have a delay in the onset of growth, have not been formulated and solved. As a consequence, although the data deviate from the theoretical curve in the fashion expected for mutants undergoing segregation lag, it cannot be said whether they are consistent with the operation of a segregation lag of any given number of generations; the data are simply inconsistent with the assumption of no segregation lag.

\section{Increase in $h^{+}$proportion during serial transfer}

An approach to the question of the length of the lag due to nuclear segregation can be made by the mutation rate calculation first used by Kaplan (1947) and by Stocker (1949). Consider a population of size $N$ in which no mutations have yet occurred. If the chance of mutation/bacterium/generation is $a$, when the population has increased to $2 \mathrm{~N}$ the number of mutants will be $2 \mathrm{Na}$ and the proportion of mutants to parents

$$
\frac{2 N a}{2 N}=1 a
$$

( $a$ is considered to be small so that $2 \mathrm{~N}$ is not greatly different from $2 \mathrm{~N}-2 \mathrm{Na}$; in which event back mutation, if it also occurs slowly, can be neglected). When $4 N$ parents are produced at the next generation, $4 N a$ new mutants will appear on the average and the old mutants will have doubled to $4 \mathrm{Na}$. The mutant proportion will then be approximately

$$
\frac{4 N a+4 N a}{4 N}=2 a \text {. }
$$

At the next generation the proportion of mutants will be $3 a$, and so on according to the relation

$$
\frac{\text { Mutants }}{\text { Parents }}=g a,
$$

where $g$ is the number of generations.

When, however, segregation lag is in operation, the rate of increase in the proportion of mutants will be slower. If we assume that segregation lag lasts for one generation, involving the separation of two nuclei, then the increase can be calculated as follows: when the number of parents is $2 N$ the proportion of mutants is

$$
\frac{2 N a}{2 N}=1 a .
$$

At the next generation the number of new mutants will be $4 \mathrm{Na}$ but the division 
of old mutants will have given rise to only $2 \mathrm{Na}$ mutant progeny. The proportion of mutants would therefore be

$$
\frac{4 N a+2 N a}{4 N}=1 \cdot 5 a
$$

After another generation the first lot of mutants will have passed through their lag and doubled to $4 N a$; the second crop, still in segregation lag, will have divided without increasing the mutant number and will, therefore, contribute only $4 N a ; 8 N a$ new mutants will have appeared through mutation. The mutant proportion will, therefore, be

$$
\frac{4 N a+4 N a+8 N a}{8 N}=2 a .
$$

The general formula for increase in proportion after the first generation is

$$
\frac{\text { Mutants }}{\text { Parents }}=\frac{g a}{2}+C_{1},
$$

where $C_{1}$ is a constant whose magnitude can be determined graphically. The denominator is always the average number of nuclei being segregated which is related to the number of generations of segregation lag, $\Delta$, by the expres$\operatorname{sion} 2^{\Delta}$.

When the segregation of four nuclei is involved and lasts 2 generations the relation for the increase beyond 2 generations is

$$
\frac{\text { Mutants }}{\text { Parents }}=\frac{g a}{4}+C_{2} \text {. }
$$

In order to determine the actual rate of increase in the proportion of $\mathrm{h}^{+}$ mutants, cultures of $\mathrm{h}^{-}$bacteria were serially transferred in the presence of histidine and allowed to accumulate $\mathrm{h}^{+}$mutants. This accumulation involved a rise in $\mathrm{h}^{+}$proportion from $10^{-7}$ to $10^{-6}$ in the course of some 150 generations. After that time the mutant proportion is maintained at a relatively constant level by the operation of periodic selection (Atwood et al. 1951). Fitter-type $\mathrm{h}^{-}$ bacteria had been isolated during the course of such pseudo-equilibrium which had persisted for thousands of generations through serial transfer. The more advanced of these fitter-type $\mathrm{h}^{-}$organisms, when used to establish a new line of serial transfer, showed increases in $\mathrm{h}^{+}$proportion that overshot the pseudoequilibrium level characteristic of the original $h^{-}$strain. Since the period of increase in the proportion of $\mathrm{h}^{+}$mutants was longer in cultures of fitter-type $\mathrm{h}^{-}$, it was possible to measure the rate of increase more accurately. Fig. 4 shows, as an example, data for the increase in $\mathrm{h}^{+}$mutants in fitter-type strain $\mathrm{h}^{-} \alpha$. The slope is linear and equal to the rate of mutation/mutable unit/ generation or to $a, \frac{1}{2} a$ or $\frac{1}{4} a$ according to the length of the segregation lag involved. Table 3 shows a summary of the results obtained with several strains where the average rate of increase in $\mathrm{h}^{+}$proportion was $0 \cdot 81 \times 10^{-8}$.

At the beginning of each of the serial transfer experiments the rate of mutation of the $\mathrm{h}^{-}$strain under consideration was determined by the Poisson method. This involved distributing to separate tubes $2 \mathrm{ml}$. samples of medium 
which had been so inoculated that each aliquot received $c .50 \mathrm{~h}-$ bacteria. The medium contained only $0 \cdot 125 \mu \mathrm{g}$. histidine $/ \mathrm{ml}$. which limited the total amount of growth to $c .2 \times 10^{7} \mathrm{~h}-$ bacteria. This level is just at the limit of visibility. The $\mathrm{h}^{+}$mutants, on the other hand, were not restricted by the limiting amount

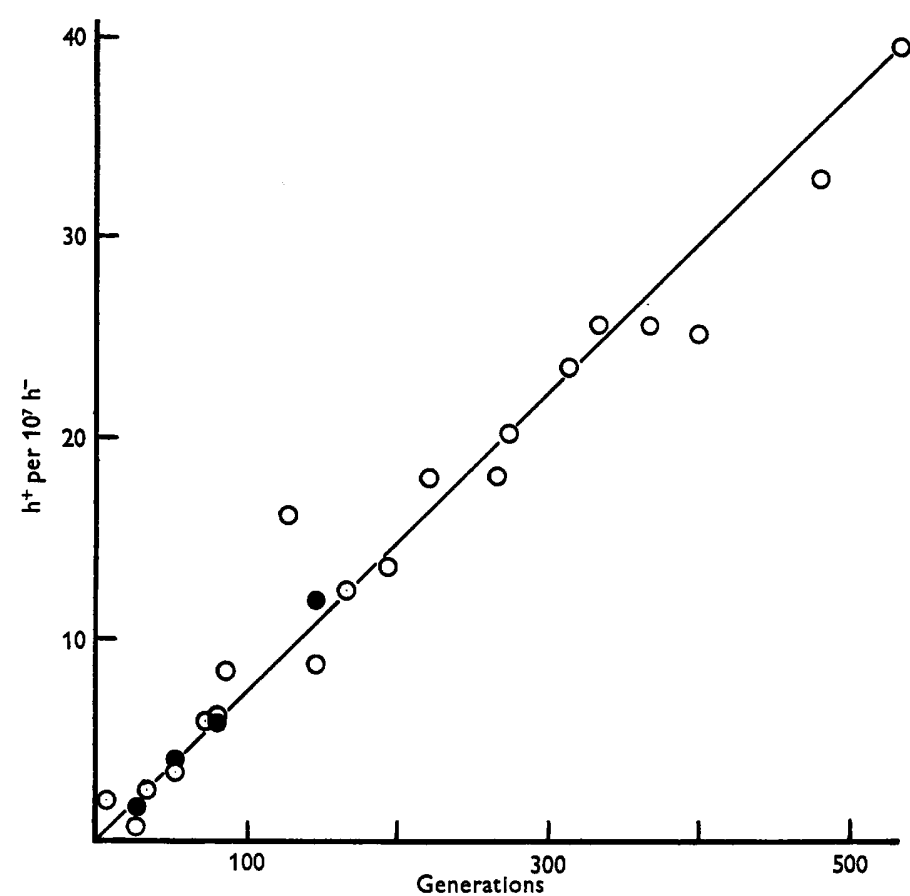

Fig. 4. The proportion of $h^{+}$mutants arising during the serial transfer of fitter-type strain $h_{\alpha}^{-}$ (open circles) in medium containing histidine. The ordinate measures the number of $h^{+}$mutants $/ 10^{7} h^{-}$bacteria; the abscissa, the number of generations of growth during serial transfer. The results were obtained from two separate experiments. The black circles describe the increase in the original $h^{-}$strain of the $h^{+}$proportion during the period of linearity before an equilibrium is achieved.

Table 3. Rates of mutation from $h^{-}$to $h^{+}$determined by two methods

\begin{tabular}{|c|c|c|c|}
\hline Strain & $\begin{array}{c}\text { Rate of increase } \\
\text { of } \mathrm{h}^{+} \text {proportion } \\
\qquad\left(\times 10^{-8}\right)\end{array}$ & $\begin{array}{c}\times^{4} \\
\left(\times 10^{-8}\right)\end{array}$ & $\begin{array}{c}\text { Rate of } \\
\text { mutation by } \\
\text { Poisson method } \\
\left(\times 10^{-8}\right)\end{array}$ \\
\hline $\mathbf{h}^{-}$ & 0.85 & $3 \cdot 4$ & $2 \cdot 7$ \\
\hline $\mathbf{h}_{\alpha}^{-}$ & 0.75 & $3 \cdot 0$ & $\mathbf{3 \cdot 2}$ \\
\hline $\mathrm{h}_{\bar{\beta}}^{-}$ & 0.83 & $\mathbf{3} \cdot \mathbf{3}$ & $3 \cdot 0$ \\
\hline $\mathbf{h}_{\gamma}^{\frac{\rho}{\gamma}}$ & 0.70 & $2 \cdot 8$ & $4 \cdot 6$ \\
\hline $\mathbf{h}_{\delta}^{\frac{\gamma}{\delta}}$ & 0.96 & $3 \cdot 8$ & $4 \cdot 2$ \\
\hline$h_{\epsilon}^{-}$ & 0.77 & $3 \cdot 1$ & $3 \cdot 1$ \\
\hline Average & 0.81 & $\mathbf{3 \cdot 2}$ & $\mathbf{3 \cdot 5}$ \\
\hline
\end{tabular}

of histidine supplied and, as a consequence, their presence in a culture was revealed by the development of heavy turbidity through adaptive overgrowth. Each experiment involved more than 100 cultures and the number of unadapted cultures was determined with the caution described in the footnote, p. 372. These 
unadapted cultures were those in which no mutation had occurred during growth. From this zero class the average number of mutations/culture could be calculated by the zero term of the Poisson formulation, $\mathrm{e}^{-m}$, where $m$ is the mean number of events. With a knowledge of $m$ and number of bacteriagenerations that had ensued, $N / \ln 2$ (the average total number of bacteria/ culture, $N$, was determined by assaying at least three unadapted cultures), the mutation rate, $a$, could be calculated by the use of the equation defining mutation rate:

$$
a=\frac{m}{N} \ln 2 .
$$

As is shown in Table 3 , the average mutation rate so determined is $3.5 \times 10^{-8} /$ bacterium/generation. It can be seen that this is almost exactly 4 times the slope of the $h^{+}$increase curves. Since the Poisson method uses only information about cultures without mutants and makes no assumption about how mutants appearing in the other cultures grow, mutation rates calculated by it are unaffected by segregation lag. The slope of the increase curve, on the other hand, is a function of the length of segregation lag. The comparison made in Table 3 shows a discrepancy that is not only inconsistent with the hypothesis of no segregation lag but is precisely that expected if segregation lag involves the separation of four mutable units and lasts two generations.

\section{DISCUSSION}

The evidence described in this paper, indicating the existence and the duration of a lag in the increase of mutant clones due to the segregation of nuclei, is rather indirect. Further, the models which were tested, being discontinuous and determinative, are at best only approximations. Other more realistic models can and have been constructed (Kendall, 1953; Armitage, 1953) but are difficult to test. There are also other conceivable differences between old and new mutants which might account for the data. Especially because data consistent with the hypothesis of a two generation segregation lag have been obtained for radiation-induced mutants by methods that directly measure the delay in the onset of growth of the mutant clone (Ryan et al. 1954), the hypothesis of a segregation delay of two generations has been accepted despite the reservations with which it must be held. This segregation lag has nothing to do with the long physiological delay observed in the division of new mutants after heavy doses of ultraviolet light (Ryan, 1954).

The operation of segregation lag has not usually been assumed in previously published methods for the calculation of mutation rate based upon numbers of mutants (Armitage, 1953). Where segregation lag is present these methods will not yield reliable figures, for segregation lag not only depresses the number of mutants but distorts their distribution. If, on the other hand, the curves that fit the data in Figs. 2 and $\mathbf{3}$ are taken to the level of one mutant on the ordinate and the total number of bacteria present at the time of the first mutation substituted in equation (9), rates of $3.5 \times 10^{-8}$ and $2.3 \times 10^{-8}$ are obtained. The average, $2.9 \times 10^{-8}$, is also not significantly different from the value $2 \cdot 7 \times 10^{-8}$ obtained by the Poisson method and shown in Table 3 .

The Poisson method would give an erroneous result if there were a physio- 
logical delay in the development of the phenotype, and some time were required for a bacterium, genotypically mutant, to become phenotypically mutant (Newcombe, 1948). If, for example, one generation were required for the expression of the phenotype, those mutations occurring during the last generation of growth would not give rise to phenotypically mutant bacteria. Since these mutations are always approximately equal in number to all that have occurred beforehand (see the models discussed above), the true rate of mutation would be underestimated by half. For reasons presented elsewhere (Ryan et al. 1954) it is believed that phenotypic lag does not operate in the system $\mathrm{h}^{-} \rightarrow \mathrm{h}^{+}$. It appears that the ability to synthesize histidine is developed in considerably less than a generation after the cell becomes genotypically $\mathrm{h}^{+}$, and, because the $\mathrm{h}^{+}$character is expressed in a heterocaryotic cell in the presence of $\mathrm{h}^{-}$genes, it is 'dominant'. This is the condition required for the action of segregation lag in the way found to be the case in the $h^{-}$to $h^{+}$mutation.

If two generations of segregation lag actually take place, if the rate of mutation from $\mathrm{h}^{-}$to $\mathrm{h}^{+}$has been accurately measured, and if periodic selection is responsible for the observed pseudo-equilibrium proportion of $h^{+}$mutants (Atwood et al. 1951), it should be possible to calculate the dynamics of change in a mutating population of $\mathrm{h}^{-}$bacteria in terms of experimentally determinable variables. The average time required for the beginning of overgrowth by fitter types of marked $h^{+}$mutants added to serially transferred $h^{-}$ cultures is about 200 generations. This, then, is the time at which the $\mathrm{h}^{+}$ mutants of spontaneous origin (and their $\mathrm{h}^{-}$parents) begin to decrease and, therefore, the time at which the pseudo-equilibrium is achieved. By the use of the formulation for two generations of segregation lag:

$$
\frac{\text { Mutants }}{\text { Parents }}=\frac{g a}{4}+C_{2} \text {, }
$$

an average mutation rate of $3 \times 10^{-8}$ and the value $\mathrm{C}_{2}$ calculated to be $4.3 \times 10^{-8}$, the substitution of 200 generations should yield the pseudoequilibrium proportion of mutants. The value calculated is $c .1 .5 \times 10^{-6}$ while that observed is $c .1 \cdot 3 \times 10^{-6}$. Thus the pseudo-equilibrium is quantitatively accounted for. The ability to describe accurately the course of change of $\mathrm{h}^{+}$ mutants in an $\mathrm{h}^{-}$population is additional evidence that the assumption of a segregation lag of two generations is valid.

Under different conditions and during different phases of the growth cycle the average number of nuclei/cell may differ (Robinow, 1945). If the nuclear bodies are, as they appear to be, the mutable units, then calculation of the mutation rate on a per bacterial cell basis would be misleading. Rather, to study environmental factors with only small effects on mutation rate it is necessary to calculate mutation rates on a per mutable unit basis. In the case of the mutation $\mathrm{h}^{-}$to $\mathrm{h}^{+}$the spontaneous rate is $c .8 \times 10^{-9}$ per mutable unit per generation during growth.

This work was supported in part by an American Cancer Society grant recommended by the Committee on Growth and by a research grant from the National Institutes of Health, U.S. Public Health Service. 


\section{REFERENCES}

Armitage, P. (1953). Statistical concepts in the theory of bacterial mutation. J. Hyg., Camb. 51, 162.

Atwood, K. C., Schneider, L. K. \& Ryan, F. J. (1951). Periodic selection in Escherichia coli. Proc. nat. Acad. Sci., Wash. 37, 146.

Cavalit, L. L., Lederberg, J. \& Lederberg, E. M. (1953). An infective factor controlling sex compatibility in Bacterium coli. J. gen. Microbiol. 8, 89.

DAvis, B. D. (1950). Studies on nutritionally deficient bacterial mutants isolated by means of penicillin. Experientia, 6,41 .

KAPLAN, R. (1947). Spontane Mutabilität bei Bacterium prodigiosum. Z. Naturf. $2 b$, 308.

KENDALL, D. G. (1953). Stochastic processes and the growth of bacterial cultures. Symp. Soc. exp. Biol. 7, 55.

Lea, D. E. \& Coulson, C. A. (1949). The distribution of the numbers of mutants in bacterial populations. J. Genet. 49, 264.

Lederberg, J. (1949). Aberrant heterozygotes in Escherichia coli. Proc. nat. Acad. Sci., Wash. 35, 178.

Lederberg, J. \& Lederberg, E. M. (1952). Replica plating and indirect selection of bacterial mutants. J. Bact. 63, 399.

LIEB, M. (1951). Forward and reverse mutation in a histidine-requiring strain of Escherichia coli. Genetics, 36, 460.

Newcomвe, H. B. (1948). Delayed expression of spontaneous mutations in Escherichia coli. Genetics, 33, 447.

Rosinow, C. F. (1945). Nuclear apparatus and cell structure in rod-shaped bacteria. Addendum in Dubos, R. J., The Bacterial Cell, Cambridge, Mass.: Harvard University Press.

Ryan, F. J. (1954). The delayed appearance of mutants in bacterial cultures. Proc. nat. Acad. Sci., Wash. 40, 178.

Ryan, F. J. \& Schneider, L. K. (1948). The consequences of mutation during the growth of biochemical mutants of Escherichia coli. J. Bact. 56, 699.

Ryan, F. J. \& Schneider, L. K. (1949). Mutations during the growth of biochemical mutants of Escherichia coli. Genetics, 34, 72.

Ryan, F. J., Fried, P. \& Schwartz, M. (1954). Nuclear segregation and the growth of clones of bacterial mutants induced by ultraviolet light. J. gen. Microbiol, 11, 380.

Stocker, B. A. D. (1949). Measurements of the rate of mutation of flagellar antigenic phase in Salmonella typhimurium. J. Hyg., Camb. 47, 398.

WiTKIN, E. (1951). Nuclear segregation and the delayed appearance of induced mutants in Escherichia coli. Cold Spr. Harb. Sym. quant. Biol. 16, 357.

Witkin, E. \& KenNedy, F. L. (1951). A suppressor mutation in Escherichia coli. Amer. Nat. 85, 141.

(Received 26 April 1954) 